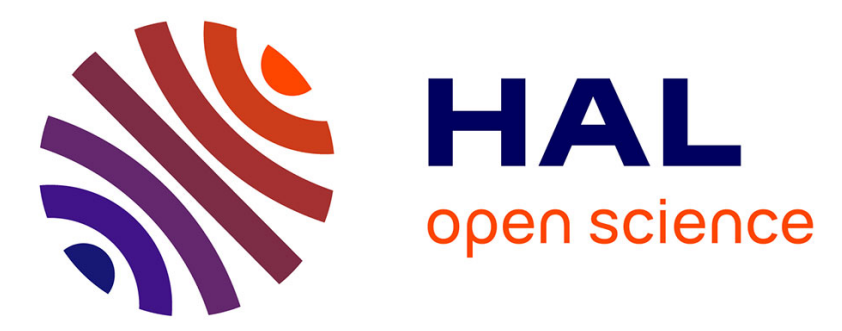

\title{
An iTV Prototype for Content Unification
}

Jorge Abreu, Pedro Almeida, Ana Velhinho, Sílvia Fernandes, Rafael Guedes

\section{- To cite this version:}

Jorge Abreu, Pedro Almeida, Ana Velhinho, Sílvia Fernandes, Rafael Guedes. An iTV Prototype for Content Unification. Esteban Clua; Licinio Roque; Artur Lugmayr; Pauliina Tuomi. 17th International Conference on Entertainment Computing (ICEC), Sep 2018, Poznan, Poland. Springer International Publishing, Lecture Notes in Computer Science, LNCS-11112, pp.293-296, 2018, Entertainment Computing - ICEC 2018. 10.1007/978-3-319-99426-0_32 . hal-02128588

\section{HAL Id: hal-02128588 \\ https://hal.inria.fr/hal-02128588}

Submitted on 14 May 2019

HAL is a multi-disciplinary open access archive for the deposit and dissemination of scientific research documents, whether they are published or not. The documents may come from teaching and research institutions in France or abroad, or from public or private research centers.
L'archive ouverte pluridisciplinaire HAL, est destinée au dépôt et à la diffusion de documents scientifiques de niveau recherche, publiés ou non, émanant des établissements d'enseignement et de recherche français ou étrangers, des laboratoires publics ou privés. 


\title{
An iTV prototype for content unification
}

\author{
Jorge Abreu ${ }^{[0000-0002-0492-2307]}$, Pedro Almeida ${ }^{[0000-0001-5878-3317]}$, Ana Velhinho ${ }^{\text {[0000-0001- }}$ \\ 9978-8317], Sílvia Fernandes [0000-0003-3221-7231], Rafael Guedes ${ }^{[0000-0002-9533-3670]}$ \\ University of Aveiro, DigiMedia, Portugal \\ \{jfa, almeida, ana.velhinho, silvia.fernandes, rafaelguedes, \} @ua.pt
}

\begin{abstract}
This paper addresses an iTV prototype able to offer contents from different sources over a unique and common user interface. The prototype was developed under the UltraTV project, formed by a consortium that gathers the industry and the academy to develop a new digital entertainment approach to the iTV ecosystem. The high-fidelity prototype runs on an Android set-top box and combines TV programs with Over-the-top (OTT) videos (from YouTube, Facebook Videos, and Netflix). The system focuses on unification, recommendation and profiling features, able to accommodate the demands of younger viewers. Adopting a User-Centered Design methodology, the development of the prototype benefited from continuous feedback obtained on different validation phases, namely a review by experts, laboratory tests, and a field trial.
\end{abstract}

Keywords: Unification, interactive TV, personalization, UX, usability.

\section{Research problem and motivational factors}

The goal of the team was to build a Set-top box (STB) based application that allowed for the unification of TV content, aiming to enhance the entertainment experience offered to different consumer profiles, including younger generations - on the one hand by providing content beyond the traditional broadcast channels to the classic TV consumers (promoting the diversification of their choices), and on the other by aiming to regain the attention in TV content and improve the quality of OTT content viewing on the large TV screen for those who are used to watch videos on their computer and mobile devices. Targeting a different approach to content 'surfing', the prototype aims to foster the discovery of content from different players and sources.

\section{2 iTV content unification demo}

\subsection{UCD prototype development}

By following an approach that included identifying the users' needs and specifying the context of use by means of characterization surveys, the development followed an iterative and continuous process. This approach allowed for the incorporation of the users' suggestions and opinions. This way, the UltraTV project followed a User- 
Centered Design methodology and took into consideration a participatory Design approach.

This process occurred across several months in which the development went through different design stages: hand drawn and digital sketches, low fidelity prototypes, midfidelity and high-fidelity STB deployments. Throughout these stages, assessments of the UI design, usability and overall User Experience were made. Following the internal validations of first sketches and low fidelity mock-ups, the research team adopted an evaluation methodology that included a review by experts[1,4], a UX lab testing phase [2] and a month-long field trial with end-users [5]. The assessment was made using several UX evaluation methods and metrics and interviews. Following laboratorial testing and continuing an iterative product design development, a functional STB-based prototype was built, supported by the user experience responses to the previous midfidelity prototype [3]. Usability and control issues were solved based on observation and the analysis of previous results.

\subsection{Functional requirements and user interface}

The Luna ${ }^{\mathrm{TM}}$ framework ${ }^{1}$, an application engine optimized for the development of context-oriented television interfaces, was chosen as the implementation platform due to its performance, graphic raw speed and time to product implementation. Luna includes a graphic engine and an API targeted to the development of TV user interfaces. Considered as a 'TV Browser', Luna allows to maximize GPU (Graphics Processing Unit) performance when compared to other HTML5 browsers. In graphical terms, it presents as main features text rendering, a set of built-in effects, 'frame-accurate' animations; resolutions up to $4 \mathrm{~K}$; and the support for 'video texture'.

Within an IPTV (Internet Protocol for Television) framework supported by the operator's channel offer, the high-fidelity version of the prototype incorporates the backend with a Web API that feeds the application with the operator's live content and video on demand, and access to the OTT sources YouTube, Facebook Videos, and Netflix. These features, when presented on a profile based TV user interface, are the starting point to create a dynamic delivery of contents, based on the user profile and consumption behaviors.

The UltraTV main screen unifies the content on a single UI (Fig. 1). This allows the user to, in a grid based navigation, have access to a diversified bundle of content with a reduced number of interactions. Content is displayed on thumbnails and cards, showing up to 140 different previews of shows, movies, and videos with no visual differentiation of the content sources. The home screen is structured into columns of content that are placed either according to genre/type of content, source or live TV. The center column displays a list of live TV channels, arranged in a traditional numbered sequence to attend to the operator's policies, while two "Suggestions" columns (TV and Web) display content based on the user's profile and viewing history.

${ }^{1}$ Craftwork Homepage, https://www.craftwork.dk/products/luna/index.html, last accessed 2018/06/01. 


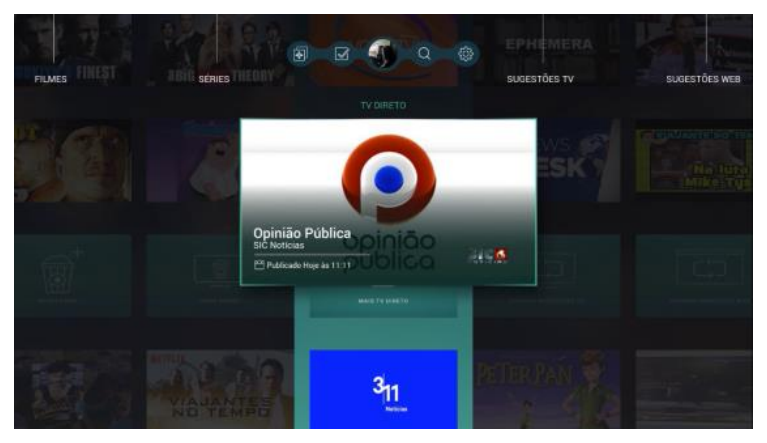

Fig. 1. Home screen interface

A unified search engine, with predictive keyboard, retrieves results from Catch-up TV and OTT sources sorted in rows, presenting labeled card-based thumbnails of the content for quick scan and access (Fig. 2).

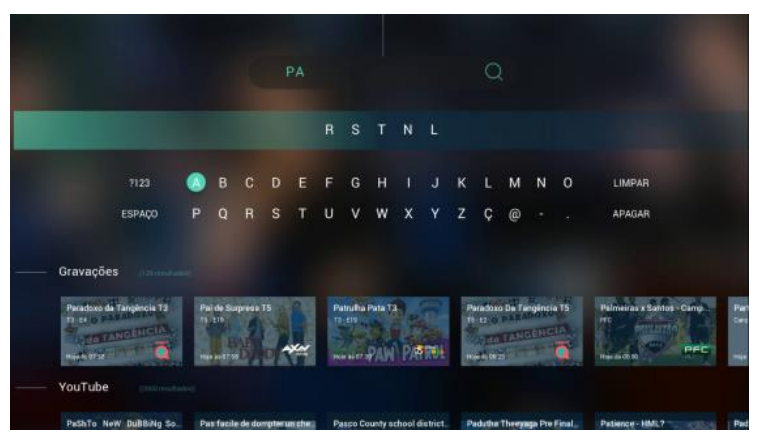

Fig. 2. Unified search interface

Additional content from different sources is suggested by several means. In full screen, the user has access to a side menu with cross reference recommendations (e.g. a YouTube video related to the TV show that's being watched) or an item page that offers similar content for the available on-demand, DVR or online sources. As shown in Fig. 3, in the home screen the user has access to another level of content by selecting a "see more" card, that takes him to a grid of the same category (e.g. the "see more Shows" section will offer every TV show available on catch-up TV and VoD, organized in different genres, according to the relevant suggestions for the active profile). Both these options create the chance for the user to explore beyond the traditional IPTV operator offer and discover new content from alternative content sources.

Furthermore, to provide a unique user experience for each profile, the suggestions are made by taking into consideration the users' choices and viewing habits. By assigning favorites or blocking content that they do not want to watch (Fig. 4), the users enhance the recommender system by directly curating their preferences. More than liking or disliking the content, the user is making the choice to save it on a favorites list (displayed in a "My Content" section), or to ask the platform to ignore it on its grid. 

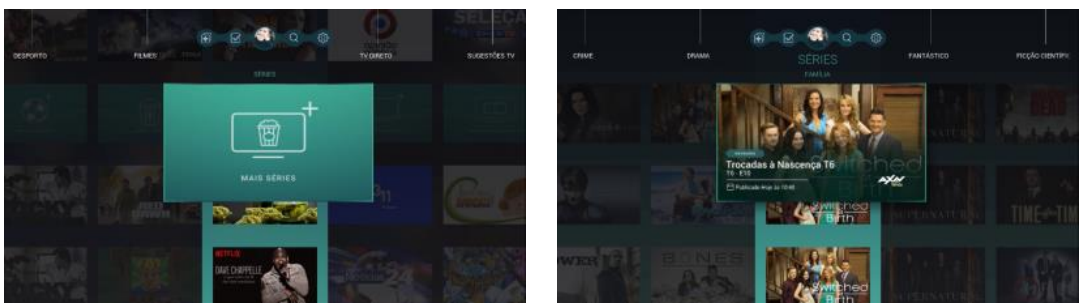

Fig. 3. "See more" card on the home screen (left), second level grid for "See more shows "(right)
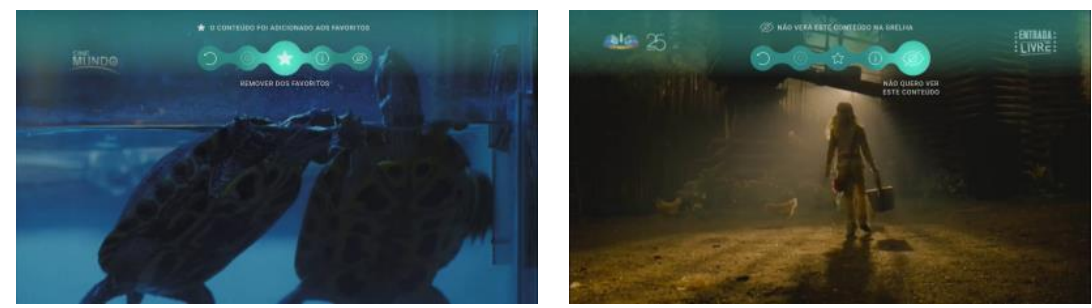

Fig. 4. Full screen menu with "Favorite" (left) and "I don't want to see this" (right) options

\section{Acknowledgments}

This paper is a result of the UltraTV - UltraHD TV Application Ecosystem project (grant agreement no.17738), funded by COMPETE 2020, Portugal 2020 and the European Union through the European Regional Development Fund (FEDER).

\section{References}

1. Jorge Abreu, Pedro Almeida, Telmo Silva, Ana Velhinho, and Silvia Fernandes. 2018. Using Experts Review to validate an iTV UI for the unification of contents. Proceedings of The 12th International Multi-Conference on Society, Cybernetics and Informatics (IMSCI 2018), Springer.

2. Pedro Almeida, Jorge Abreu, Telmo Silva, et al. 2018. Iterative User Experience Evaluation of a User Interface for the Unification of TV Contents. In Applications and Usability of Interactive Television. Springer, Aveiro, 44-57.

3. Pedro Almeida, Jorge Abreu, Telmo Silva, et al. 2018. UltraTV: an iTV content unification prototype. Proceedings of the ACM International Conference on Interactive Experiences for TV and Online Video - TVX '18, ACM.

4. Pedro Almeida, Jorge Ferraz de Abreu, Eliza Oliveira, and Ana Velhinho. 2017. Expert evaluation of a user interface for the unification of TV contents. Proceedings of the 6th Iberoamerican Conference on Applications and Usability of Interactive TV - jAUTI 2017, Universidade de Aveiro, 59-70.

5. Pedro Almeida, Abreu Jorge, Sílvia Fernandes, and Eliza Oliveira. 2018. Content Unification in iTV to Enhance User Experience: The UltraTV Project. Proceedings of the ACM International Conference on Interactive Experiences for TV and Online Video - TVX '18, ACM. 